\title{
ALGUNOS PROBLEMAS DEFINITORIOS Y TERMINOLÓGICOS EN EL ÁMBITO DE ESTUDIOS FRASEOLÓGICOS ESPAÑOLES
}

\begin{abstract}
A b s r a c t. Szałek Jerzy, Algunos problemas definitorios y terminológicos en el ámbito de estudios fraseológicos españoles [Some definitional and terminological problems in the field of Spanish phraseological studies]. Studia Romanica Posnaniensia, Adam Mickiewicz University Press, Poznań, vol. XXIX: 2003, pp. 215-221, ISBN 83-232-1232-5, ISSN 0137-2475.

The article discusses some of the essential theoretical and terminological issues in contemporary studies of Spanish phraseology and phraseography. The controversial definitional problems of Modern Spanish phraseology have been presented on the basis of concepts of indiscreet and cognitive interpretation. The examples provided come from contrastive Spanish-Polish phraseology.
\end{abstract}

Los problemas de carácter definitorio y terminológico dentro de los estudios fraseológicos españoles se nos presentan cada día más urgentes e importantes, dado el estado actual de las investigaciones sobre fraseología, una rama lexicológica que, en los últimos años, ha dejado de ser aislada atrayendo un nuevo interés entre hispanistas de diversos centros de investigación lingüística (consúltese a modo de ejemplo toda una serie de trabajos más o menos recientes: Corpas Pastor 1996, Ruiz Gurillo 1997, 1998, Wotjak (ed.) 1998, García-Page 1989 y siguientes).

Como es sabido, la fraseología como una ciencia cada vez más independiente de la lexicología se ha convertido últimamente en un amplio campo de estudios multifacéticos aprovechando en sus estudios abundantemente de diferentes métodos e instrumentos de las demás ciencias lingüísiticas.

En España, por su parte, la fraseología no tuvo tanta suerte como en algunos otros países europeos como Rusia y Francia, porque su consolidación teórica desde que Julio Casares sentó sus bases en los años cincuenta, no se había llevado a cabo. Sin embargo, y a pesar de los pesares, hoy en día la situación en el ámbito fraseológico y fraesográfico español está cambiando considerablemente y en fin de 
cuentas se contemplan nuevos rumbos y enfoques orientados hacia una plena visión del conjunto de los problemas ligados a la fraseología española contemporánea.

Uno de esos enfoques alentadores proviene de los mismos investigadores españoles. Me refiero, p.ej., a los últimos intentos de recoger lo que podríamos denominar una "nueva teoría fraseológica" por parte del grupo de investigación Val.Es.Co. de la Universidad de Valencia, la teoría no discreta de las unidades fraseológicas desde las perspectivas amplia y estrecha, respectivamente, así como la del ordenamiento de las propiedades fraseológicas más significativas, las de la fijación y la idiomaticidad (véase Ruiz Gurillo 1997, 1998, 1998a).

Otro trabajo de suma importancia, que vale la pena citar a modo de ejemplo, es el de G. Corpas Pastor (1997), quien, al seguir algunas consideraciones anglosajonas, propone una nueva tipología de unidades fraseológicas en español, y da una pormenorizada descripción del ámbito de la fraseología, tratando de asimilar el término "colocación", poco adaptable al español. Dicho sea de paso, la utilización de términos ambiguos tipo "colocación" o "solidaridades léxicas" que provienen del campo de estudios léxicos, no me parece demasiado satisfactoria para la teoría fraseológica del español porque en mi opinión, la selectividad o combinatoriedad ( $=$ relaciones combinatorias de diferente índole, en polaco: taczliwość frazeologiczna) de los constituyentes de un conjunto de palabras fraseológicas presenta siempre un complejo abanico de restricciones formales, sintagmáticas y semánticas no sólo en un tipo determinado de las UFS, sino en todos los niveles taxonómicos, tanto idiomáticos como extrafraseológicos.

Los problemas más difíciles en cuanto a terminología, taxonomía y definición se refiere, surgen con más agudez a la hora de profundizar la extensión de las mismas propiedades fraseológicas en unidades propias de los lenguajes específicos o epeciales, p.ej., en las del lenguaje periodístico (Szałek 1997).

Resulta muy problemático, si no del todo imposible, trazar los límites entre diferentes unidades, especialmente, entre las de la "periferia" (extrafraseológicas) o distinguir de una manera acertada entre los niveles taxonómicos:

- fónico-fonológico (p.ej., la disposición silábica, rítmica, ortográfica, etc.),

- categorial-funcional (p.ej., locuciones nominales/loc. verbales, loc. adverbiales/loc. adjetivales, etc.),

- sintagmático y morfológico (p.ej., las irregularidades estructurales y las restricciones de fijación con distribución aleatoria),

- léxico-semántico (p.ej., el sentido idiomático o idiomaticidad/el sentido abstracto, la motivación/la no motivación, la existencia de una variante homófona literal, la presencia o no de elementos constituyentes diacríticos),

- pragmático (las esferas diatópica, diastrática y diafásica).

En lo que atañe a las propiedades fraseológicas, hay que señalar que hasta hoy día tanto en la investigación española como en la de otros autores europeos no se pueden poner los puntos sobre los íes, porque las definiciones que se producen en abundancia, no parecen relevantes en todos los casos. Al tenerlo en cuenta, 
M. Olejarová (2000: 99-104) propone p.ej., un estudio individualizado de las locuciones idiomáticas, basándose en un corpus ilimitado sometido a un procesamiento electrónico.

Los problemas definitorios y terminológicos de la investigación fraseológica en el ámbito español se deben a algunos factores que deseo, en este lugar, esbozar brevemente. Empezaré por enumerar aquellas circunstancias que, en mi opinión, han contribuido considerablemente a crear una visión poco transparente y confusa. Las consecuencias, sin embargo, no ocasionan tan sólo los problemas en el campo teórico fraseológico, sino también en el lexicográfico-fraseográfico y/o didáctico:

- El enfoque tradicionalmente léxico o lexicográfico de los estudios hispánicos sobre la formación de conjuntos de palabras en español.

- La breve historia de la fraseología en español recoge corrientes diferentes y multifacéticas tanto en la Península, en los diversos países europeos, como en Hispanoamérica (p.ej., la aportación de Julio Casares, la contribución de algunos de los autores del Este y del Centro de Europa (en la antigua URSS, Alemania, Checoslovaquia), la escuela cubana de A.M. Tristá y Z. Carneado Moré (desde los años 70 del siglo pasado), el estudio de A. Zuluaga (1980) sobre las propiedades básicas de las expresiones fraseológicas en español, los trabajos de M. García-Page (desde 1989 hasta hoy día, tanto sobre temas paremiológicoas como fraseológicos propiamente dichos), los de I.Bosque y J.Martínez Marín, etc. (Para más detalles, consúltese, entre otros, un minucioso y cronológico repertorio en L. Ruiz Gurillo (1997: 17-32)).

- El problema en la gradación y la delimitación de unidades fraseológicas.

- La falta de criterios teóricos específicos en el corpus fraseológico del Diccionario de la Real Academia Española, en el del Diccionario de Uso del Español de María Moliner, así como en las demás grandes obras lexicográficas españolas, las de carácter monolingüe y bilingüe, respectivamente.

- El glosario terminológico fraseológico típicamente español varía según autores desde el mismo tếrmino de unidad básica de estudio hasta los que se refieren a las particularidades específicas y los fenómenos de fraseologización e idiomatización (compárese p.ej., algunas de las definiciones de la siguiente serie de términos: locución-frase hecha-modismo-idiotismo-frase proverbial-refrán-dichoproverbio, etc.).

- La falta de un gran diccionario fraseológico de la lengua española moderna desde una concepción ancha y estrecha de la fraseología (es curioso que en las obras que hay se confunden criterios en la delimitación de unidades o se siguen unas tendencias nuevas, pero de una manera selectiva y poco consecuente, véase p.ej., Varela, Kubarth 1994: VII-XV).

- La abundancia de recientes propuestas taxonómicas exige una coordinación entre especialistas procedentes de diversos centros de estudios fraseológicos en español. 

europea.

- La falta de estudios temáticos y contrastivos en la fraseología hispánica y/o

- El problema de ambigüedad terminológica en los trabajos sobre fraseología.

- La transliteración de términos.

No cabe duda de que la lengua española pertenece a las lenguas más ricas en unidades fraseológicas. El caudal fraseológico español en forma de lexemas unimembres metaforizados y los pluriverbales se guarda minuciosamente en obras lexicográficas o paremiológicas desde hace siglos. Basta con recordar el Tesoro de la lengua española de Sebastán de Covarrubias que data del año 1611 o el Diccionario de Refranes, Adagios y Locuciones Proverbiales de José María Sbarbi (1851), las cuales se recopilan y citan en multitud de trabajos lexicográficos. Una de las obras modernas de este tipo es la de J.M. Iribarren (1997 [1956]), que ha conseguido hasta hoy día diez ediciones. En el estudio introductorio a la última edición de El porqué de los dichos, José María Romera apunta acertadamente:

La variedad de términos empleados a lo largo de la historia para referirse a lo que genéricamente denomina Iribarren dichos puede dar idea de la vidriosa ambigüedad del terreno explorado: dichos, modismos, refranes, locuciones, frases hechas, sentencias, aforismos, tópicos, adagios, apotegmas, máximas, son algunas de las palabras traídas y llevadas en los diccionarios y en la conversación ordinaria sin fijar a cada una un contenido preciso, que tampoco los estudiosos han puesto mucho interés en deslindar, tal vez por la inasible condición de la materia a que se refieren. (Romera, Estudio Introductorio en Irribaren 1997: XVI).

La difícil tarea de discernir en español entre diferentes tipos de entidades fraseológicas se debe, en primer lugar, al hecho de los confusos límites de la fraseología como ciencia lingüística. Hay que recordar aquí que hasta no hace mucho los diccionarios especializados no incluían el término fraseología entre sus entradas y, si lo hacían tal vez, se referían únicamente al mismo caudal fraseológico de la lengua, sin precisar adecuadamente el ámbito de su estudio actual. En los últimos estudios se observan, sin embargo, algunos esfuerzos para adoptar el término genérico de la unidad básica en los estudios fraseológicos. La lengua española, además de poseer muchos términos "tradicionales" para referirse a distintos tipos de combinaciones de palabras, tiene la facilidad de asimilar muchísimas propuestas neológicas, lo que no facilita la tarea de unificación y estandarización terminológica. En los estudios recientes, los de carácter científico se utilizan p.ej., unidad fraseológica, expresión fraseológica, expresión fija, expresión pluriverbal, fraseologismo, unidad pluriverbal, etc. (cf. p.ej., Corpas Pastor (1997: 17-18), quien ofrece una relación de términos por orden cronológico). Teniendo en cuenta el criterio de aceptabilidad terminológica de Guerrero Ramos (1995: 15-16), según el cual "en terminología lo más importante es que el término técnico o científico entre en funcionamiento, que sea aceptado por el conjunto de especialistas de una disciplina a fin de facilitarles la intercomprensión y, sobre todo, 
que estos expertos lo utilicen en sus medios habituales de expresión", parece que los términos arriba aducidos pueden ser considerados como apropiados. No obstante, en mi opinión, la denominación más adecuada sería unidad fraseológica (o fraseologismo), por ser más generalizada tanto para el ámbito de estudio español como el europeo occidental u oriental (sobre esta opinión, véase p.ej., Castillo Carballo 1997: 137).

El término unidad fraseológica lo encontramos, entre otros, en un buen estudio de Leonor Ruiz Gurillo (1997), quien lo define de la siguiente manera:

la denominación unidad fraseológica hace referencia a una combinación fija de palabras que presenta algún grado de fijación y eventualmente de idiomaticidad. La elección de dicho término, frente a otros como expresión fija y frase hecha, se debe a diversas razones, como su afinidad con la denominación de fraseología, su alta frecuencia de aparición en ciertos estudios lingúísticos o su mayor adecuación a la idiosincrasia de dichas combinaciones... (Ruiz Gurillo 1997: 14).

Aunque la autora no se dedica en especial a los problemas terminológicos, no deja de señalar algunas de las ambigüedades que existen en el uso de términos ligados a las propiedades fraseológicas, p.ej., la denominación de palabras diacríticas de A. Zuluaga (1980) frente a la de palabras idiomáticas de M. García-Page (1991) (véase Ruiz 1998: 12-13).

Las palabras en cuestión se refieren a las ya reconocidas por muchos autores propiedades de fijación e idiomaticidad, consideradas hoy por hoy como las características más determinativas de las unidades fraseológicas. Sin embargo, las dificultades que surgen a la hora de diferenciarlas o relacionarlas mutuamente, no han sido superadas del todo. Así que, el establecimiento de niveles o grados siempre resulta difícil, debido a la complejidad del proceso de fraseologización. Al tener en cuenta que la fijación es un rasgo indispensable para cualquier unidad fraseológica, aunque bien es cierto que puede revelarse también en otras unidades lingüísticas, parece que la idiomaticidad, o mejor dicho el mismo proceso de "idiomatización", puede dar algunas "nuevas pistas" para esclarecer mejor el fenómeno de la fraseologización. Ruiz Gurillo (1997), siguiendo a diferentes autores, define el fenómeno de fraseologización como "el proceso por medio del cual, gracias a la fijación en algún grado y en ocasiones a la idiomaticidad, parcial o total, se constituye una unidad fraseológica" (Ruiz 1997: 104). En este estudio las precisiones del término idiomaticidad, junto a las de motivación de un fraseologismo me parecen un poco ambiguos y poco transparentes. En mi opinón, el fenómeno de la "no composicionalidad semántica" hay que considerarlo como uno de los problemas más complejos y a la vez más controvertidos en la teoría fraseológica europea. A este respecto, p.ej., Klimaszewska (1996: 107-112), al investigar la idiomatización en el holandés y al optar por un análisis semántico cognitivo que se apoya en la teoría de prototipos, cuestionó la convicción sobre la arbitrariedad de algunos fraseologismos idiomáticos (cf. Zuluaga (1980: 128), quien 
propone una doble arbitrariedad). Según esta autora un significado menos prototípico de sus constituyentes supone una mayor idiomaticidad del conjunto.

Como quiera que sea, los grados de idiomaticidad en un continuum del caudal fraseológico se revelan bastante claramente. Comparemos a modo de ejemplo la siguiente serie de unidades fraseológicas con el mismo o parecido significado idiomático que en conjunto se refiere a una situación hipotética de "no tener dinero", "estar sin dinero", de "estar muy escaso de dinero o carecer de toda clase de recursos":

grado I bailar el pelado (1)

estar a la cuarta pregunta (2)

grado II estar a dos velas /quedarse (o andar) a dos velas/ (3)

estar sin cinco /no tener ni cinco/ (4)

grado II/III estar pelado (5)

estar sin blanca /no tener blanca/ no valer una blanca (6) estar sin un cuarto (7)

grado IV estar (quedarse) sin una perra /no tener una perra/ estar sin un real (8) no tener un céntimo (9)

La unidad fraseológica idiomática en (I) con palabra diacrítica pelado<pela supone una total idiomaticidad del conjunto de palabras. Según Irribaren (1997: 143), es muy probable que el bailar la pela aluda a una antigua costumbre gallega del Corpus Christi de llevar un individuo pobre sobre los hombros a un niño ricamente adornado.

Las unidades del II grado, por su parte, representan un tipo propiamente idiomático al poseer en su estructura grupos con motivación bastante oscurecida: la cuarta pregunta, dos velas y cinco. Las explicaciones en este caso tampoco parecen satisfactorias (aunque existen varias, cf. Irribaren que sigue a Sbarbi (1997: 46-47; 126). La palabra "cinco" los autores de diccionarios la asocian con los dedos de la mano y la de pelado proviene, sin duda, de pelar. Dicho sea de paso, según las últimas investigaciones la aparición del verbo estar en las unidades fraseológicas afirmativas resulta muy rentable, especialmente en los esquemas: "estar + prep." y/o "estar+adj.", y en comparación con el verbo ser, estar es más predicativo que atributivo (veáse Rebollo Torío 2000: 433-441).

Las unidades del grupo IV, ligadas a la idea de una moneda, las considero como escasamente idiomáticas. Si comparamos la serie idiomática española de nuestro ejemplo con las de otras lenguas, la configuración u ordenamiento de grados idiomáticos siempre presentará otra imagen. Compárense p.ej., la selecta serie de equivalencias idiomáticas en polaco: być sptukanym, zostać bez złamanego szelaga, nie śmierdzieć groszem, zostać bez grosza przy duszy, być krucho z pieniędzmi, nie mieć ani grosza. 
Y para concluir, hay que señalar que junto a las tareas de unificación y estandarización terminológica, que hacen falta en la investigación fraseológica española, es preciso seguir profundizando en una completa visión del fraseologismo o unidad fraseológica, así como en los mismos mecanismos de fraseologización (entre otras la relación entre la fijación e idiomaticiad). Creo que el avance será más eficaz desde diversos enfoques interdisciplinares y comparativos. Desde una perspectiva fraseográfica urge muchísimo llevar a cabo dichas tareas.

\section{BIBLIOGRAFIA}

Cast 1110 Ca r ballo, M.", A. (1998), Un nuevo tipo de locuciones: las adjetivo-adverbiales en G.Wotjak (ed.), Estudios de fraseología y fraseografía del español actual, p. 137.

Cor p a s Pas tor, G. (1997), Manual de fraseología española, Madrid, Gredos.

Ga r cía-Page Sã nchez, M. (1991), Locuciones adverbiales con palabras "idiomâticas", "Revista Española de Lingüística" 1991, (2), pp. 233-264.

I r r i b a r e n, J.M. (1997 [1956]), El porqué de los dichos. Pamplona, Departamento de Educación y Cultura del Gobierno de Navarra.

K 1 i mas zewska, Z. (1996), Proces idiomatyzacji na przykladzie języka niderlandzkiego [El proceso de idiomatización en la lengua neerlandesa] en A.M, Lewicki (ed.), Problemy frazeologii europejskiej [Problemas de fraseologia europea], Warszawa, Energeia, pp. 107-112.

Martínez Marín, J. (1196), Estudios de fraseología española (serie: "Cuadernos de lingüistica"), Málaga, Editorial Librería Ágora.

O l e j a r o vá, M. (2000), Las propiedades de las locuciones idiomáticas en A. Pamies Bertrán y J. de Dios Luque Durán (eds.), Trabajos de lexicografía y fraseología contrastivas, Departamento de Lingüística General y Teoria de Literatura de la Universidad de Granada, Granada, pp. 99-104.

Rebollo Torío, M.A. (2000), Ser y estar en las frases hechas, "Anuario de Estudios Filológicos" XXIII, pp. 433-441.

R u z Gurillo, L. (1997), Aspectos de fraseología teórica española. "Cuadernos de filología", anejo n. ${ }^{\circ}$ XXIV, Universidad de Valencia, Valencia.

- (1998), La fraseología del español coloquial, Barcelona, Editorial Ariel.

- (1998a), Una clasificación no discreta de las unidades fraseológicas del español en G. Wotjak (ed.),

Estudios de fraseología y fraseografía del español actual, pp.13-37.

$\mathrm{Sz}$ ałe k, J. (1997), Los clichês periodísticos como unidad fraseológica más típica de los textos informativos españoles, "Studia Romanica Posnaniensia" 22, pp. 171-178.

$\mathrm{V}$ a r e l a, F., K u b a r t h, H. (1994), Diccionario fraseológico del español moderno, Madrid, Gredos.

Wotjak, G. (1998), Estudios de fraseología y fraseografía del español actual. Lingüística Iberoamericana, Vol. 6, Frankfurt am Main, Vervuert-Madrid, Iberoamericana.

$\mathrm{Z}$ u l u a g a, A. (1980), Introducción al estudio de las expresiones fijas, Tubingen, M. Hueber.

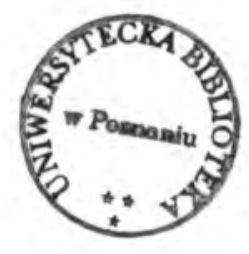

